\title{
Thermo-catalytic degradation of different plastics to drop in liquid fuel using calcium bentonite catalyst
}

\author{
Achyut K. Panda ${ }^{1}$
}

Received: 18 July 2017 / Accepted: 2 June 2018 / Published online: 7 June 2018

(c) The Author(s) 2018

\begin{abstract}
Thermal and catalytic pyrolysis of individual plastics such as polypropylene (PP), low-density polyethylene (LDPE), highdensity polyethylene (HDPE), and mixture of all three plastics (PP + LDPE + HDPE) were carried out in the presence of calcium bentonite as catalyst in a batch reactor to obtain suitable liquid fuel. The dependencies of process temperature, effect of catalyst, feed composition on yield of the fuel fraction were determined. The major product of both thermal and catalytic pyrolysis was condensable fraction in the temperature range $400-550{ }^{\circ} \mathrm{C}$. The reaction rate, quality and quantity of the major products changed with change of temperature and catalyst concentration. The highest yield of pyrolysis liquid product was $88.5 \mathrm{wt} \%$ from PP, $82 \mathrm{wt} \%$ from LDPE, $82.5 \%$ from HDPE and $81 \mathrm{wt} \%$ from mixed plastics at $500{ }^{\circ} \mathrm{C}$ with $1: 3$ catalyst to plastic ratio. The oil obtained in this process was analyzed using FTIR and GC-MS for its composition. Fuel properties of the oil are evaluated to understand its uses as a fuel or chemical feedstock.
\end{abstract}

Keywords Pyrolysis $\cdot$ Plastics $\cdot$ Catalyst $\cdot$ Calcium bentonite $\cdot$ Fuel

\section{Introduction}

The use of plastic materials in the present context appear beyond sustainable development as they are manufactured from non-renewable petroleum products, have low life cycle during their uses and are non-biodegradable, accrued in landfills and in natural habitats worldwide, causing different environmental problems. Suitable reuse and recycling technique or waste-reduction strategies are the need of the hour, as it is impossible to avoid the use of plastics altogether due to their diversified applications [1]. Among different plastic waste management options, pyrolysis is getting attention as it provides an opportunity of transforming waste plastic materials of low-energy density into high-energy density fuels and recovery of high value chemicals. Pyrolysis involves thermochemical decomposition of organic material in the absence of oxygen or in an atmosphere of inert gases. Compared to combustion, pyrolysis has a lower process temperature and negligible emissions of air pollutants. Additionally, this process has the ability to handle unsorted,

Achyut K. Panda

achyut.panda@gmail.com

1 Department of Chemistry, Veer Surendra Sai University of Technology Burla, Odisha 768018, India unwashed plastic, thus could become the most promising to be developed into a plastic waste to energy recycling process [2].

Catalytic pyrolysis of waste plastic has significant advantages over thermal as the catalyst help lowering temperatures, enhancing the reaction rate and yield fuels in the gasoline to diesel range, thus eliminating the necessity of further processing. Zeolitic materials are extensively researched catalysts in plastic pyrolysis used by different researchers and found to achieve higher conversion than non-zeolitic catalysts owing to their strong acidity, pore size and pore structure. Natural clinoptilolite, acid-treated clinoptilolite, mordenite, $\mathrm{H}$-mordenite, Na-mordenite, $\mathrm{H}-\mathrm{Y}$ zeolites, Na-Y zeolites, H-ZSM-5, REY zeolites, H-USY zeolites, HY zeolite, ZSM-5, desilicated ZSM-5 (DeZSM-5) and lanthanum-incorporated ZSM-5 (LaZSM-5) are different zeolitic catalyst reported in plastic pyrolysis. In addition, alumina, silica, $\mathrm{MoO}_{3}$ mixed silica, BEA, MCM-41, HMCM-41, clay, FSM, SAHA, FCC, lead sulfide, Fly ash-derived amorphous silica-alumina catalysts, calcium carbide, zinc oxide and homogeneous mixture of silica and alumina, $\mathrm{BaO}, \mathrm{MgO}$, $\mathrm{Fe}_{2} \mathrm{O}_{3}$, etc. are some non zeolitic catalysts explored to understand their catalytic activity. Clay catalysts unlike other have been reported to possess high thermal stability and proper pore dimension for cracking but have very low acidity 
required for cracking [1, 2]. Some of the works reported by various researchers recently are summarised as follows:

The thermal and catalytic pyrolysis of LDPE, HDPE, PP, polyethylene terephthalate (PET) and polystyrene (PS) plastics were studied individually and in mixed ratios with PS in a $25 \mathrm{~cm}^{3}$ stainless steel autoclave micro-tubular reactor at around $430-440{ }^{\circ} \mathrm{C}$ under $5.5-6.0 \mathrm{MPa}$ of $\mathrm{N}_{2}$ gas pressure for $1 \mathrm{~h}$. The result indicated that ratio $1: 1$ afforded best results in the form of conversion. In all catalytic co-processing of mixed plastics, ratio 1:1 afforded the best yields in the form pyrolytic oils [3]. Stefanis et al. have tested the performance of three restructured smectite clays, namely a saponite, a montmorillonite, and a beidellite, as well as their Al- and Fe/Al-pillared derivatives in the catalytic cracking of a medium-density polyethylene. All reduce the cracking process temperature and found superior with regards to liquid hydrocarbon formation [4]. Pyrolysis of HDPE waste products was investigated using both thermal and catalytic cracking techniques using packed bed reactor with bed materials, including sand, cement and white clay in the presence of catalysts sodium hydroxide, HUSY and HBeta zeolite, under an inert atmosphere at $450{ }^{\circ} \mathrm{C}$. The reactor beds significantly altered the yield as well as the product composition with yield of $82 \%$ liquid over a cement powder bed with narrowing of product distribution using the zeolitic catalysts [5]. Catalytic pyrolysis of high-density polyethylene (HDPE) using metal oxides $\left(\mathrm{Fe}_{2} \mathrm{O}_{3}, \mathrm{CoO}\right.$, $\mathrm{ZnO}, \mathrm{MnO}_{2}$ and $\mathrm{NiO}$ ) impregnated waste brick kiln dust to obtain petro-fuels like oil. ZnO-impregnated catalyst was found to be highly active in terms of oil quality and yield [6]. Synergistic interactions of calcium oxide $(\mathrm{CaO})$ or calcium hydroxide $\left(\mathrm{Ca}(\mathrm{OH})_{2}\right)$ and a steam atmosphere were studied in the thermal decomposition of individual and mixed plastics (PE, PP, PS and PET) at $600{ }^{\circ} \mathrm{C}$. The presence of steam with $\mathrm{CaO}$ facilitated the $\mathrm{PE}, \mathrm{PP}$ and mixed plastic cracking while decreasing the PS cracking process [7]. Miandad et al. studied the two-step pyrolysis (thermal followed by catalytic) of high-density polyethylene using mixture of MCM41 and ZSM-5 as catalyst for producing oil. Mixture of equal amount of both the catalysts with plastic and catalyst ratio of 1:2 yielded highest $83 \%$ oil containing aromatic hydrocarbons with a few aliphatic hydrocarbon compounds [8]. The presence of Fe-PILC among a series of modified pillared clays as catalyst in the pyrolysis of mixed plastics enhanced the oil yields with about $80 \%$ selectivity for diesel fraction and high yield of $\mathrm{H}_{2}$ gas owing to moderate acidity, high surface area and uniform distribution of iron oxide over montmorillonite support [9]. Catalytic pyrolysis of different plastics (PS, PP, PE and their mixture at $450{ }^{\circ} \mathrm{C}$ and $75 \mathrm{~min}$. Was carried out in a small pilot reactor using natural and synthetic zeolite as catalyst yielding $>50 \%$ yield. The pyrolytic oils of high heating values consisting of mostly aromatic hydrocarbons with few aliphatic hydrocarbons are obtained in the process [10]. Akubo et al. reported the catalytic pyrolysis of high-density polyethylene (in a fixed bed reactor at a temperature of $600{ }^{\circ} \mathrm{C}$ using transition metalimpregnated Y-zeolite catalysts. The catalysts were found to promote the yield of aromatic hydrocarbons in the oil fraction with filamentous-type carbon deposition on it [11]. Both acid- and alkaline-treated ZSM-5 zeolite were used as a catalyst for the pyrolysis of PP:PE mixture at $450{ }^{\circ} \mathrm{C}$ for 30 min. Alkaline-treated catalyst yielded higher lighter fractions composed of olefins, alkylbenzenes and naphthalenes with the predominance of olefins [12]. PE and PP were subjected to thermal and catalytic degradation in a batch reactor at $450{ }^{\circ} \mathrm{C}$ using ultra-stable $\mathrm{Y}$ (USY) zeolite in a ratio of 1:10. The non-catalytic pyrolysis of PE and PP yielded $80 \mathrm{wt} \%$ of wax and $85.5 \%$ of liquid, respectively, while the addition of catalyst yielded 71 and $82 \mathrm{wt} \%$ liquid products only, respectively [13]. Organically modified montmorillonite was used as catalyst in the thermal degradation of mixed plastics consisting of polypropylene, polyethylene and polystyrene at $700{ }^{\circ} \mathrm{C}$ into valuable hydrocarbons [14]. Aluminium-containing mesoporous MCM-41 and SBA-15 was used as catalyst in the thermal degradation of polypropylene in a semi-batch reactor. Both the catalysts showed selectivity for lighter hydrocarbons with $<\mathrm{C}_{14}$ [15]. Waste plastic samples (consisting of HDPE, PP and PS) from landfill site were subjected to thermal and catalytic pyrolysis at $450{ }^{\circ} \mathrm{C}$ in a batch reactor to produce plastic oil. The oil yield of HDPE, PP and PS was found to be $80,82.6$ and $80 \%$ by weight, respectively while that in silica-alumina-catalysed reaction (with catalyst to feedstock ratio of 1:10) was the most effective in terms of gaseous fraction production [16].

Manos et al. used two smectites, a saponite and a montmorillonite, and their Al-pillared derivatives, in the cracking of polyethylene [17]. In our previous studies, we have extensively studied the use of kaoline and acid-treated kaolin in the cracking of different plastics [18]. In both the studies, it is found that the clay catalysts are less active than zeolitic catalysts at low pyrolysis temperature, but act better than zeolite at higher temperature. In this work, we report the thermal degradation of different commodity plastics such as LDPE, HDPE and PP and their mix over another clay material calcium bentonite as catalyst. The plastic oil obtained at optimum condition was characterized for its composition and physical properties.

\section{Experimental programme}

We used the virgin plastic pellets $(2.5 \mathrm{~mm}$ in size $)$ of three different types of plastics polypropylene (PP), low-density polyethylene (LDPE), and high-density polyethylene (HDPE) procured from Reliance Industries Limited, India. Virgin PP, HDPE and LDPE used in the experiment have 
density and melt flow index (MFI) values of $0.905 \mathrm{~g}$ cc and $8-9 \mathrm{~g} / 10 \mathrm{~min}^{-1}, 0.954 \mathrm{~g} \mathrm{cc}$ and $1.20 \mathrm{~g} / 10 \mathrm{~min}^{-1}$, and $0.917 \mathrm{~g} \mathrm{cc}$ and $7 \mathrm{~g} / 10 \mathrm{~min}^{-1}$ (at $230{ }^{\circ} \mathrm{C}$ and $2.16 \mathrm{~kg}$ load), respectively. The calcium bentonite clay used in this experiment was obtained from Benzenikx Pharma and Industrial Products Pvt. Ltd., Hyderabad, India.

The calcium bentonite clay material was characterized by X-ray fluorescence spectroscopy (XRF), X-ray diffraction (XRD), scanning electron microscope (SEM) and by sorptometric studies. The XRF of the sample was taken using Model-PW2400 of Phillips make, with X-ray tube of rhodium anode and scintillation detector with a current $40 \mathrm{~mA}$ and voltage $40 \mathrm{mV}$. The X-ray diffraction data was collected using a Philips analytical X-ray instrument, X'PertMPD (PW 3020 vertical goniometer and PW 3710 MPD control unit) employing Bragg-Brentano para focusing optics and XRD patterns were recorded in the range of $10-70^{\circ}$ with a scanning rate of $2 \% \mathrm{~min}$. The surface area of the clay sample was measured by Nitrogen adsorption-desorption measurements (BET method) were performed at liquid nitrogen temperature $\left(-196{ }^{\circ} \mathrm{C}\right)$ with an autosorb BET apparatus from Quantachrome Corporation. Scanning electron micrograph was taken on a JEOL-JSM 5600LV microscope. The acid properties of the catalysts were probed by ammonia TPD measurements in Micromeritics 2900 TPD equipment.

The pyrolysis experiments were carried out in a batch reactor system (Fig. 1a) made up of a $300 \mathrm{ml}$ stainless steel ampule (Fig. 1b) heated to the desired temperature at a heating rate of $20{ }^{\circ} \mathrm{C}$ per minutes externally by a vertical furnace and a $\mathrm{Cr}-\mathrm{Al}$ : K-type thermocouple and an external PID controller for regulating the temperature. The stainless steel ampule consisting of two parts: (i) bottom vessel for holding sample and (ii) an outlet for discharge of pyrolysis products joined together by grafoil-gasketed flange joints. The outlet tube is connected to the water-cooled glass condenser for condensing the pyrolysis gaseous products. Experiments were carried out using four types of plastic samples such as
PP, HDPE, LDPE and mixed plastics (PP + HDPE + LDPE in the proportion 1:1:1 by weight) and in catalytic pyrolysis, a mixture of catalyst in different catalyst to plastic ratio and the plastic samples were taken in the bottom vessel. The stainless steel ampule was first evacuated using a vacuum pump and then inserted inside the furnace heating chamber after attaining the predefined temperatures ranging from 400 to $550{ }^{\circ} \mathrm{C}$. The temperature range for the pyrolysis was defined from the thermogravimetric results reported in our previous works and in the other literatures. The condensable liquid products were collected through the water-cooled glass condenser and weighed. After pyrolysis, the solid residue left out inside the reactor was weighed. Then, the weight of gaseous product was calculated from the material balance. The pyrolysis experiments were repeated for three times to obtain reproducible results.

The FTIR spectrum of the oil product was obtained in a Bruker Alpha FTIR spectrophotometer with spectral range $500-4000 \mathrm{~cm}^{-1}$, resolution $2 \mathrm{~cm}^{-1}$, DLATGA detector, Universal $\mathrm{ZnSe}$ ATR, gold-coated mirrors, ZnSe beam splitter and window and OPUS software for analysis of the sample to know the functional group composition of the sample. The samples are analyzed directly on the Universal $\mathrm{ZnSe}$ ATR plate. The components of liquid product were analysed using GC-MS-QP 2010 (Shimadzu) using flame ionization detector. Helium gas was used as carrier gas at flow rate of $1.50 \mathrm{ml} / \mathrm{min}$. The oven initial temperature was set to $70{ }^{\circ} \mathrm{C}$ for $2 \mathrm{~min}$ and then increased to $300^{\circ} \mathrm{C}$ at a rate of $10^{\circ} \mathrm{C} / \mathrm{min}$ and maintained for 7-8 min.

\section{Results and discussion}

\section{Catalyst characterisation}

The XRF composition of the calcium bentonite clay is $\mathrm{SiO}_{2}: 53.02, \mathrm{Al}_{2} \mathrm{O}_{3}: 20.34, \mathrm{Fe}_{2} \mathrm{O}_{3}: 9.39, \mathrm{TiO}_{2}: 1.14, \mathrm{Na}_{2} \mathrm{O}$ :
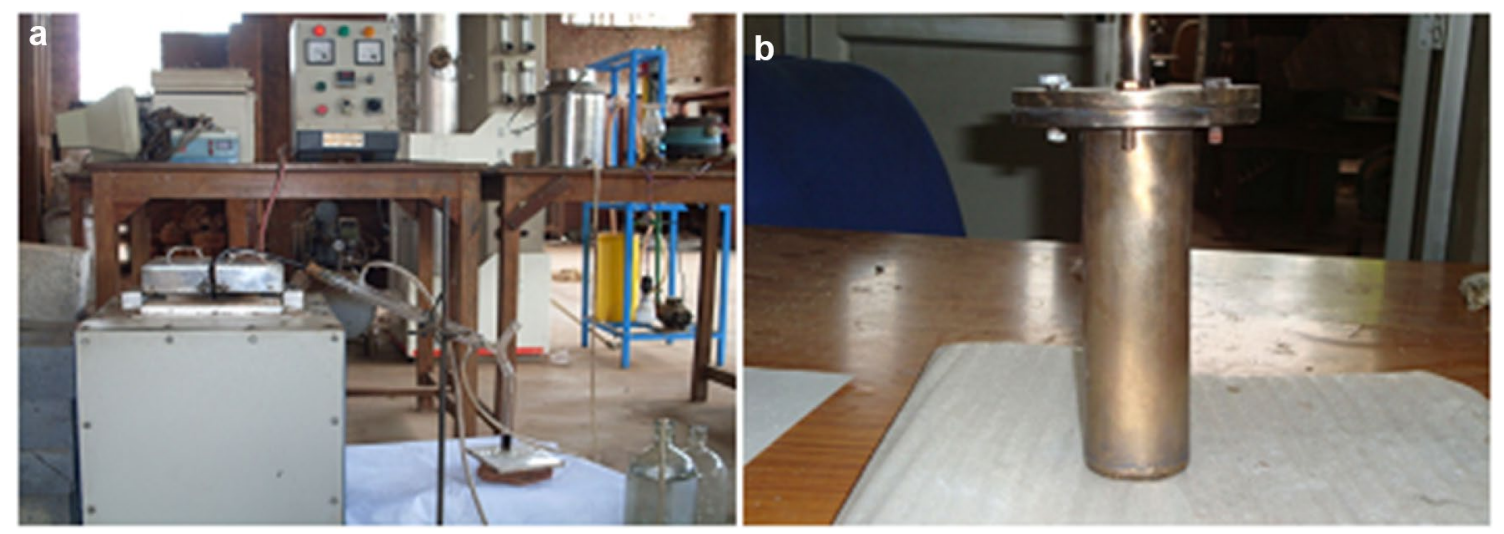

Fig. 1 a Pyrolysis set up with stainless steel reactor, b stainless steel ampule 
0.33, $\mathrm{CaO}: 4.85, \mathrm{P}_{2} \mathrm{O}_{5}: 0.03, \mathrm{~V}_{2} \mathrm{O}_{5}: 0.09, \mathrm{MnO} 0.08$, LOI: 10.72. The parent clay shows (Fig. 2) well-defined reflections at $2 \theta$ value of $30^{\circ}$, these peaks correspond to the reflections from [0 01 1], which is the typical characteristic peak of calcium bentonite. The scanning electron micrograph of the clay sample is presented in Fig. 3 which reveals the presence of particles in the form of agglomerates with porous surface morphology.

The BET surface area of the clay was found to be $146 \mathrm{~m}^{2} / \mathrm{g}$. The TG plot (Fig. 4) of the clay sample ensures the thermal stability, as there is small weight loss up to $700{ }^{\circ} \mathrm{C}$, which must be due to physio-adsorbed water only and thus the clay could be used in pyrolysis below $700{ }^{\circ} \mathrm{C}$. The TPD ammonia acidity of clay sample was found to be $57.2 \mu \mathrm{mol} / \mathrm{g}$.

\section{Effect of temperature and catalyst}

The pyrolysis was conducted in a stainless steel reactor system as described in the experimental section using calcium bentonite as catalyst at various temperatures in the range $400-550{ }^{\circ} \mathrm{C}$. The pyrolysis of plastic samples yielded three different products: (i) the major product includes a volatile oil at lower temperature $\left(400\right.$ and $\left.450{ }^{\circ} \mathrm{C}\right)$ or a waxy oil at and above $475{ }^{\circ} \mathrm{C}$, (ii) the next major fraction constitute combustible non-condensable gas, and (iii) very small amount of solid residue. The plastic type and temperature significantly affected the product distribution as summarised in Fig. 5. Low-vapour residence time and improper cracking at higher temperature resulted in the formation of high molecular mass oligomers leading to formation of waxy product. On the other hand, at lower temperature range, more vapour residence time facilitate secondary cracking resulted in highly volatile product. The optimum temperature for obtaining higher yield of condensable fraction for

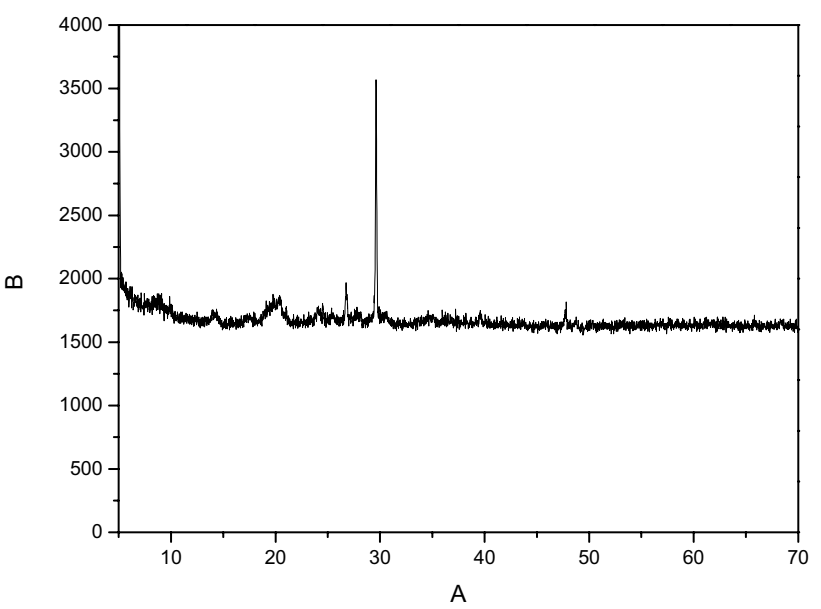

Fig. 2 XRD plot of calcium bentonite

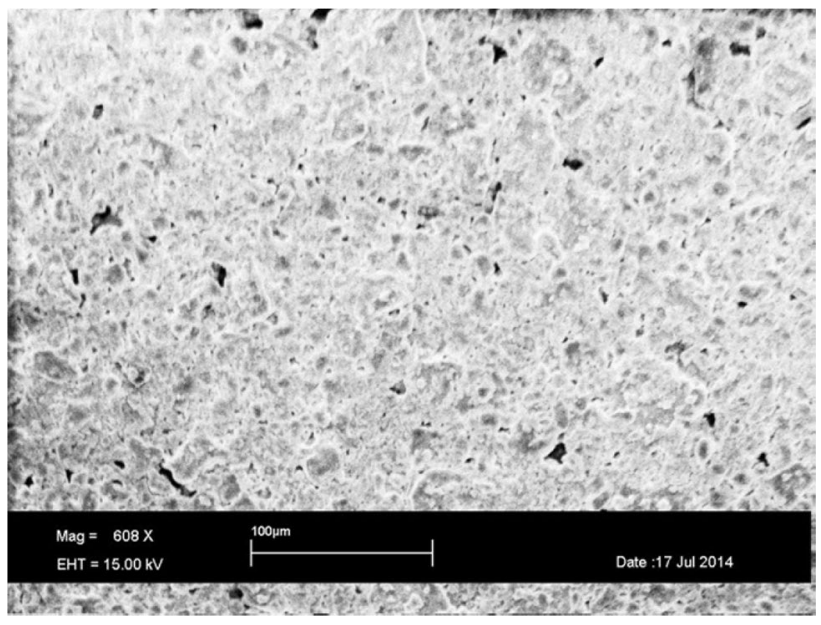

Fig. 3 SEM of calcium bentonite

all types of plastics and mixed plastics was $500{ }^{\circ} \mathrm{C}$. For all types of plastics, the condensable fraction was either higher viscous liquid (PP) and waxy product (HDPE and LDPE) at $500{ }^{\circ} \mathrm{C}$ in thermal pyrolysis. So further reactions were carried out at $500{ }^{\circ} \mathrm{C}$.

The effect of temperature on the reaction kinetics of different plastics at different temperatures was studied for different plastics. The pyrolysis reaction rate increased and thus reaction time decreased with increase in temperature. High temperature easily breaks the bonds and thus speeds up the reaction and lowers the reaction time. The reaction kinetics for different plastics followed the trend HDPE $>$ LDPE $>$ PP at all the temperature range. This can be explained on the basis of the strength of the $\mathrm{C}-\mathrm{C}$ bond and orientation of polymer chain in different plastics. HDPE with long linear polymer chain with low branching and high degree of crystallinity has high strength and thus required more time

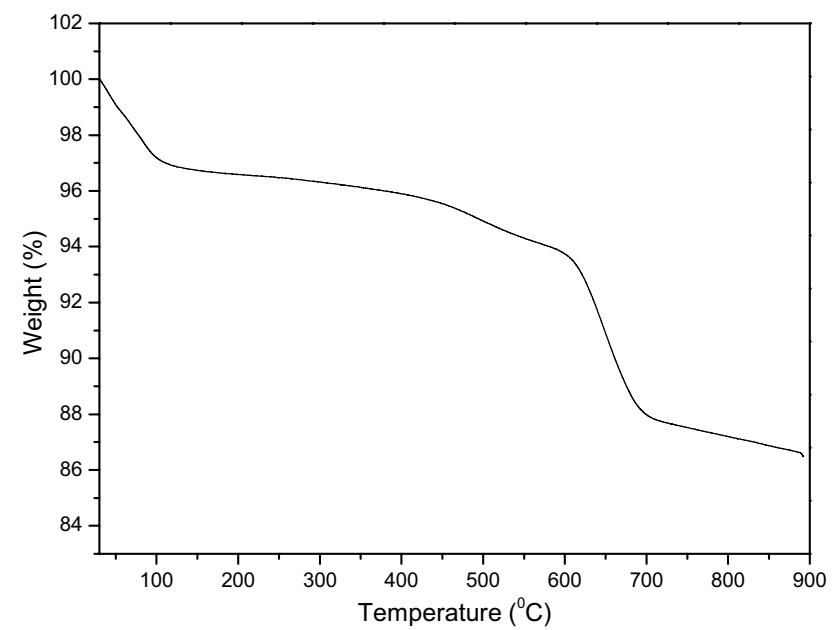

Fig. 4 TGA analysis of calcium bentonite 

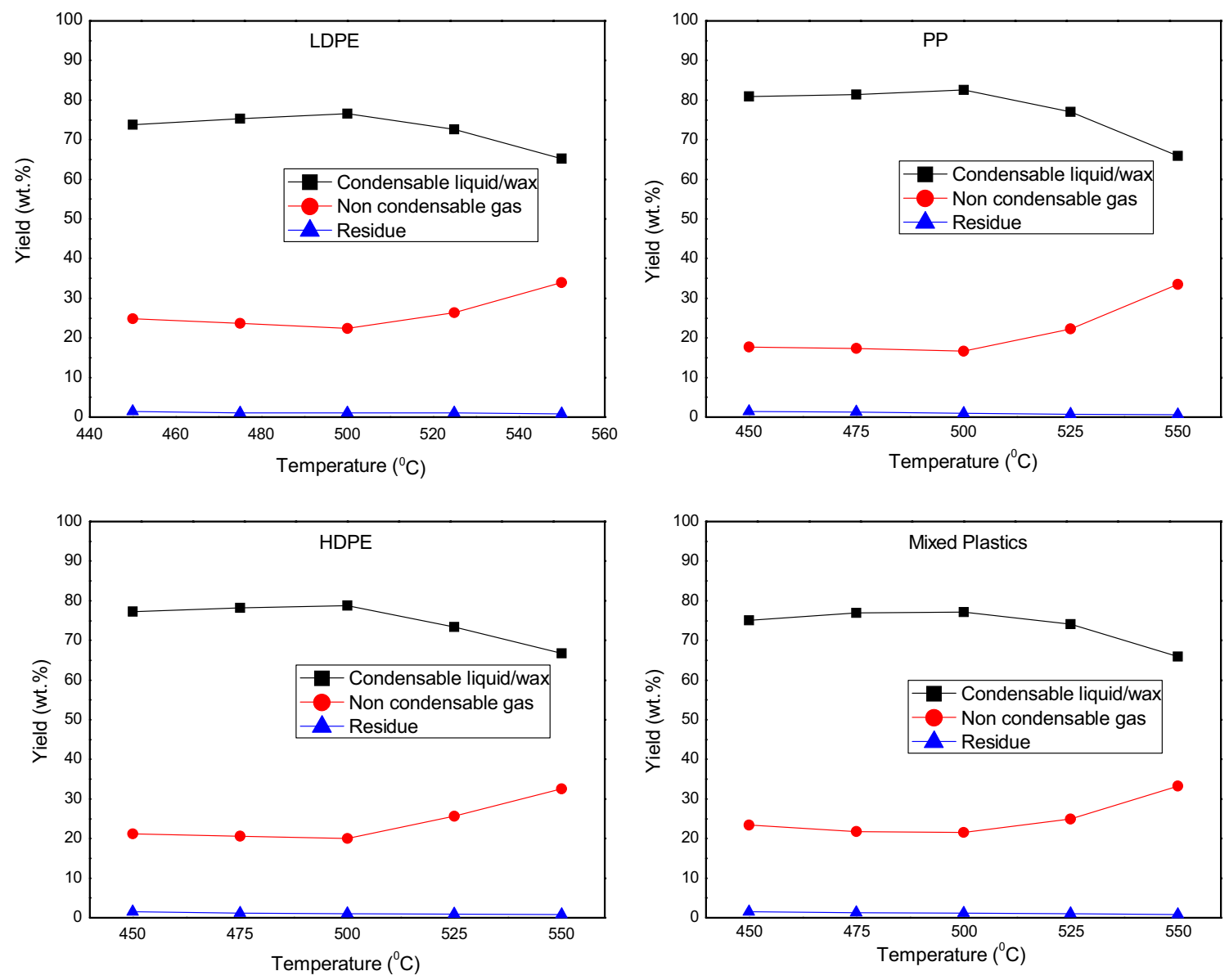

Fig. 5 Product distribution at different temperatures for different plastics

for decomposition. Whereas LDPE with high branching and low crystallinity has weak bonds which are easily broken compared to HDPE. In PP, the presence of side chain group $\left(-\mathrm{CH}_{3}\right)$ and low crystallinity decreases the overall strength, leading to lower reaction time.

The presence of calcium bentonite catalyst significantly affected the rate of reaction as well as the quality of condensable fraction. The condensable fraction was volatile oil from all plastic types in the presence of calcium bentonite catalyst which was either wax or viscous liquid in thermal pyrolysis. The reaction time for catalytic pyrolysis of different plastics decreased with increase in catalyst concentration (Fig. 6). This infers that the rate of reaction increased with increase in catalyst concentration, owing to the high surface area and acidity of the catalyst. Yield of oil increased in presence of catalyst and it was further increased with increase in concentration of catalyst. The effect of catalyst concentration on the product distribution for different plastics is summarised in Fig. 7. The effect of catalyst was very small with $1: 20$ catalyst to plastic ratio (5\% catalyst concentration). The optimum catalyst concentration for the maximum oil yield was 1:3 catalysts to plastics ratio (33.3\%

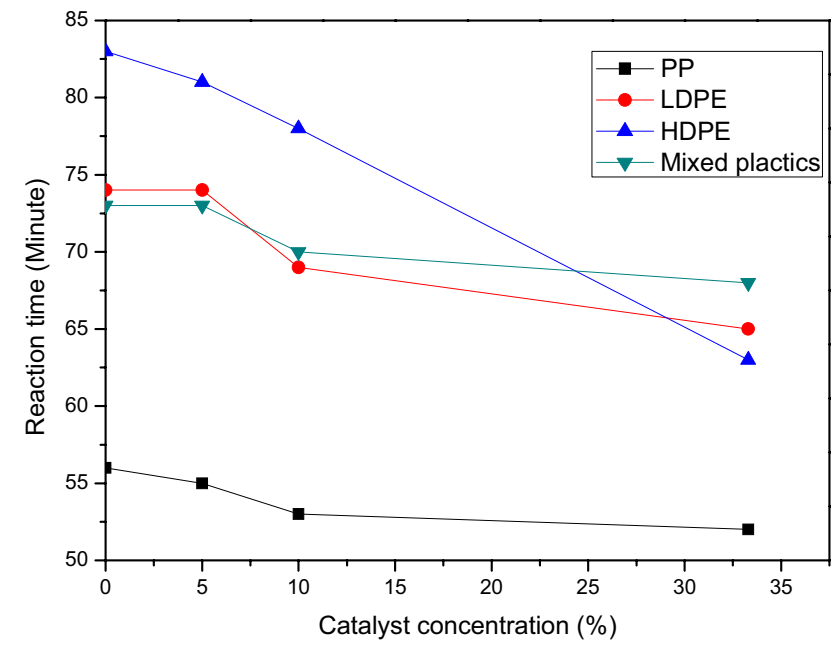

Fig. 6 Effect of catalyst conc. on the reaction time for different plastics at $500{ }^{\circ} \mathrm{C}$

catalyst concentration) at $500{ }^{\circ} \mathrm{C}$. The maximum yield of oil in the optimum condition of temperature and catalyst concentration was $88.5 \mathrm{wt} \%$ from PP, $82 \mathrm{wt} \%$ from LDPE, 

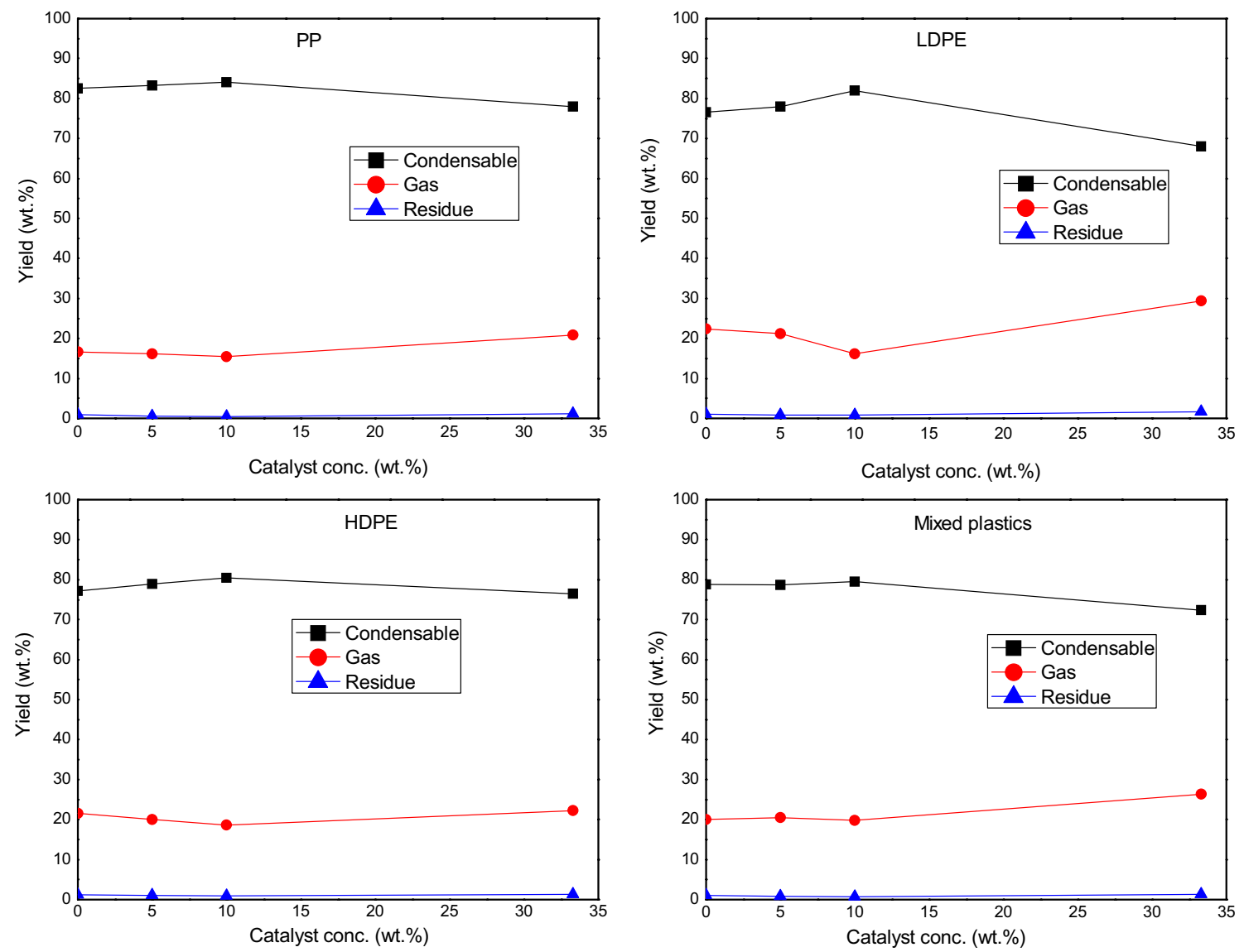

Fig. 7 Effect of catalyst conc. on the product distribution for different plastics at $500{ }^{\circ} \mathrm{C}$

Table 1 Effect of catalyst concentration on the specific gravity of the oil at $500{ }^{\circ} \mathrm{C}$

\begin{tabular}{llll}
\hline $\begin{array}{l}\text { Catalyst: plastic } \rightarrow \\
\text { Type of plastics } \downarrow\end{array}$ & $1: 20$ & $1: 10$ & $1: 3$ \\
\hline PP & 0.757 & 0.750 & 0.721 \\
LDPE & 0.832 & 0.789 & 0.769 \\
HDPE & 0.853 & 0.822 & 0.789 \\
PP + LDPE + HDPE (1:1:1) & 0.82 & 0.781 & 0.751 \\
\hline
\end{tabular}

82.5\% from HDPE and $81 \mathrm{wt} \%$ from mixed plastics. More catalyst might facilitate the better cracking of plastics to condensable fractions, yielding more oil products and less gaseous fraction. This is also supported by the fact that, increase of catalyst concentration decreased the specific gravity of the oil due to the formation of lighter fraction (Table 1).

\section{Chemical composition of plastic oil}

The chemical composition of the plastic oil was obtained by FTIR and GC-MS techniques. The FTIR of the oil samples obtained from the optimum condition of catalytic

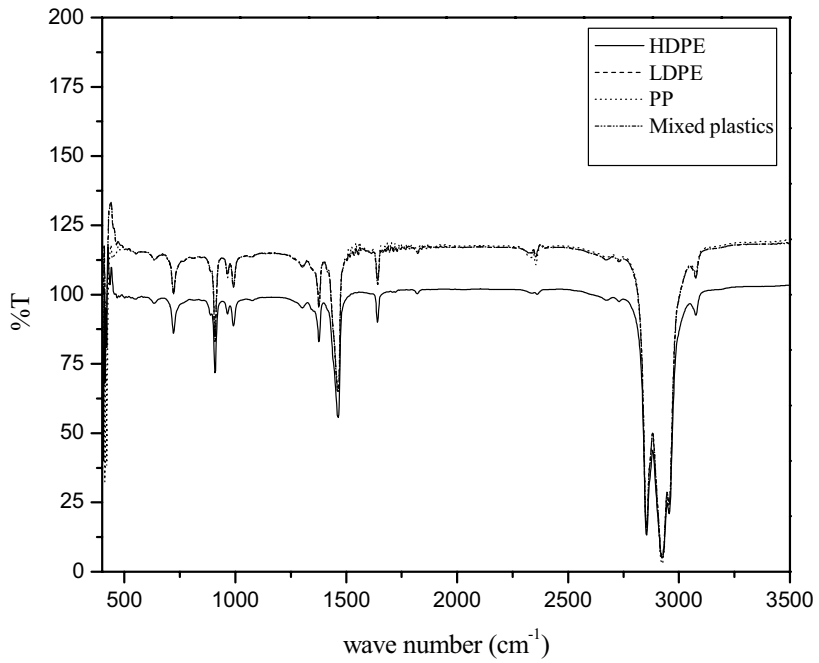

Fig. 8 FTIR plot of different plastics oils obtained at optimum reaction temperature and catalyst

pyrolysis of different plastics are reported in Fig. 8. The results show the presence of almost similar functional group composition of the oil obtained from HDPE, LDPE, 
PP and mixed plastics. The major peaks infer the presence of aliphatic hydrocarbons $\left(\mathrm{C}-\mathrm{H}_{\text {stretching }}: 2850-2960 \mathrm{~cm}^{-1}\right.$, $\left.\mathrm{C}-\mathrm{H}_{\mathrm{def}}: 1380 \mathrm{~cm}^{-1}\right)$ and olefins $\left(\mathrm{C}=\mathrm{C}_{\text {stretching }}\right.$ alkene: $1450-1494 \mathrm{~cm}^{-1}$ and $\mathrm{C}-\mathrm{H}_{\mathrm{def}}: 897-970 \mathrm{~cm}^{-1}$ ).

The GC-MS plot of the oil obtained from the mixed plastics obtained at optimum condition is shown in Fig. 9 and the components in the oil are reported in Table 2. The oil consists of a number of different hydrocarbons with
$\mathrm{C}_{10}-\mathrm{C}_{28}$. The major components being 5-decene, decane, 4-methyl-2-heptene, 4-dodecene, 3-undecene, dodecane, 6-tridecene, undecane, tridecane, tetradecane, pentadecane, 1-heptadecene, hexadecane, heptadecane, octadecane, nonadecane, heptadecane, tetracosane, tetracosane, octacosane, docosane, etc. The result of the GC-MS studies is also supported by the literature. The thermal degradation of polyethylene and polypropylene proceed via a

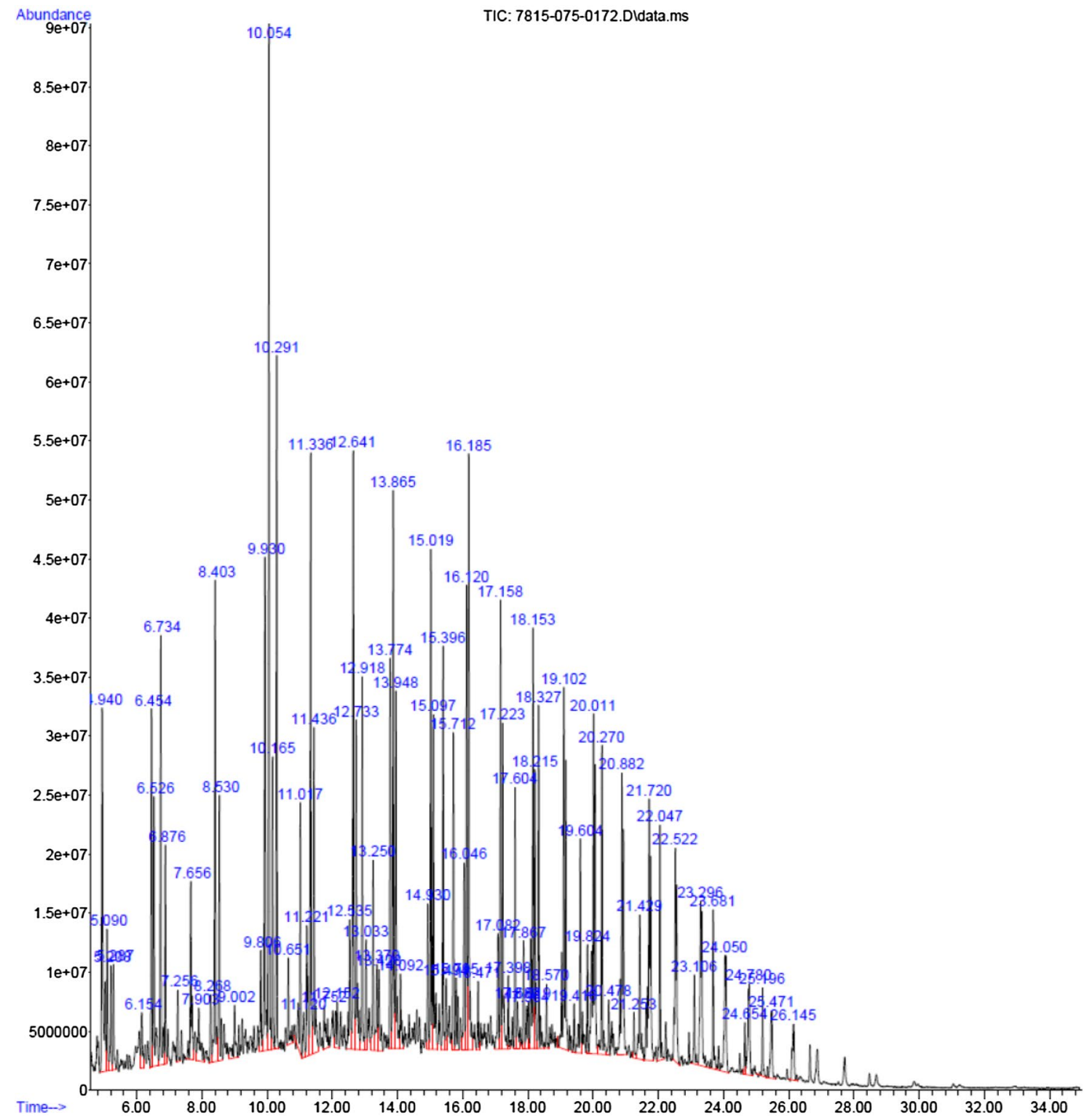

Fig. 9 GC-MS of the oil from mixed plastics 
Table 2 GC-MS Composition of oil from mixed plastics

\begin{tabular}{|c|c|c|c|c|}
\hline Sl. no. & Retention time & Area & Compound & Molecular formula \\
\hline 1 & 4.936 & 2.31 & 1-Decene & $\mathrm{C}_{10} \mathrm{H}_{20}$ \\
\hline 2 & 5.092 & 0.62 & Decane & $\mathrm{C}_{10} \mathrm{H}_{22}$ \\
\hline 3 & 5.211 & 0.53 & Nonane, 2,6-dimethyl- & $\mathrm{C}_{11} \mathrm{H}_{24}$ \\
\hline 4 & 5.285 & 0.46 & Decane, 4-methyl- & $\mathrm{C}_{11} \mathrm{H}_{24}$ \\
\hline 5 & 6.452 & 1.46 & 1-Hexene, 3,3-dimethyl- & $\mathrm{C}_{8} \mathrm{H}_{16}$ \\
\hline 6 & 6.526 & 1.36 & 3-Heptene, 4-methyl- & $\mathrm{C}_{8} \mathrm{H}_{16}$ \\
\hline 7 & 6.734 & 1.94 & 1-Undecene & $\mathrm{C}_{11} \mathrm{H}_{22}$ \\
\hline 8 & 6.875 & 0.80 & Undecane & $\mathrm{C}_{11} \mathrm{H}_{24}$ \\
\hline 9 & 7.254 & 0.30 & 2,2-Dimethyl-3-heptene & $\mathrm{C}_{9} \mathrm{H}_{18}$ \\
\hline 10 & 8.272 & 0.36 & 4-Undecene, 10-methyl-, & $\mathrm{C}_{12} \mathrm{H}_{24}$ \\
\hline 11 & 8.405 & 2.18 & 1-Dodecene & $\mathrm{C}_{12} \mathrm{H}_{24}$ \\
\hline 12 & 8.532 & 1.20 & Dodecane & $\mathrm{C}_{12} \mathrm{H}_{24}$ \\
\hline 13 & 9.000 & 0.46 & Decane, 2-methyl- & $\mathrm{C}_{11} \mathrm{H}_{24}$ \\
\hline 14 & 9.809 & 0.51 & 4-Undecene & $\mathrm{C}_{11} \mathrm{H}_{22}$ \\
\hline 15 & 9.928 & 2.29 & 1-Tridecene & $\mathrm{C}_{13} \mathrm{H}_{26}$ \\
\hline 16 & 10.054 & 4.29 & Hexane, 2,3,4-trimethyl- & $\mathrm{C}_{9} \mathrm{H}_{20}$ \\
\hline 17 & 10.166 & 1.05 & Hexane, 2,3,4-trimethyl- & $\mathrm{C}_{9} \mathrm{H}_{20}$ \\
\hline 18 & 10.292 & 2.62 & Hexane, 1,2,4-trimethyl- & $\mathrm{C}_{9} \mathrm{H}_{20}$ \\
\hline 19 & 10.649 & 0.42 & 3-Decene, 2,2-dimethyl- & $\mathrm{C}_{12} \mathrm{H}_{24}$ \\
\hline 20 & 11.020 & 1.13 & Trimethyl-, 3-ethyl-3-octene & $\mathrm{C}_{13} \mathrm{H}_{29}$ \\
\hline 21 & 11.221 & 0.81 & 3-Tetradecene & $\mathrm{C}_{14} \mathrm{H}_{28}$ \\
\hline 22 & 11.332 & 2.68 & 1-Tetradecene & $\mathrm{C}_{14} \mathrm{H}_{28}$ \\
\hline 23 & 11.436 & 1.45 & Tetradecane & $\mathrm{C}_{14} \mathrm{H}_{30}$ \\
\hline 24 & 12.149 & 0.47 & 7-Tetradecene & $\mathrm{C}_{14} \mathrm{H}_{28}$ \\
\hline 25 & 12.640 & 2.67 & 1-Pentadecene & $\mathrm{C}_{15} \mathrm{H}_{30}$ \\
\hline 26 & 12.736 & 1.60 & Pentadecane & $\mathrm{C}_{15} \mathrm{H}_{32}$ \\
\hline 27 & 12.914 & 1.38 & 1-Undecene, 7-methyl- & $\mathrm{C}_{12} \mathrm{H}_{24}$ \\
\hline 28 & 13.249 & 0.89 & 1-Undecene, 7-methyl- & $\mathrm{C}_{12} \mathrm{H}_{24}$ \\
\hline 29 & 13.776 & 1.62 & 1,7-Nonadiene, 4,8-dimethyl- & $\mathrm{C}_{11} \mathrm{H}_{20}$ \\
\hline 30 & 13.865 & 2.40 & Cetene & $\mathrm{C}_{16} \mathrm{H}_{32}$ \\
\hline 31 & 13.947 & 1.59 & Hexadecane & $\mathrm{C}_{16} \mathrm{H}_{34}$ \\
\hline 32 & 14.088 & 0.41 & 5-Undecene, 7-methyl- & $\mathrm{C}_{12} \mathrm{H}_{24}$ \\
\hline 33 & 15.017 & 2.08 & 1-Heptadecene & $\mathrm{C}_{17} \mathrm{H}_{34}$ \\
\hline 34 & 15.099 & 1.67 & Heptadecane & $\mathrm{C}_{17} \mathrm{H}_{36}$ \\
\hline 35 & 15.492 & 0.35 & Tetradecane & $\mathrm{C}_{14} \mathrm{H}_{30}$ \\
\hline 36 & 16.124 & 1.93 & 1-Octadecene & $\mathrm{C}_{18} \mathrm{H}_{36}$ \\
\hline 37 & 16.183 & 2.65 & Octadecane & $\mathrm{C}_{18} \mathrm{H}_{38}$ \\
\hline 38 & 17.156 & 1.78 & 1-Nonadecene & $\mathrm{C}_{19} \mathrm{H}_{38}$ \\
\hline 39 & 17.223 & 1.48 & Nonadecane & $\mathrm{C}_{19} \mathrm{H}_{40}$ \\
\hline 40 & 18.018 & 0.18 & 1-Heptadecene & $\mathrm{C}_{17} \mathrm{H}_{34}$ \\
\hline 41 & 18.152 & 2.13 & 1-Nonadecene & $\mathrm{C}_{19} \mathrm{H}_{38}$ \\
\hline 42 & 18.211 & 1.18 & Hexadecane & $\mathrm{C}_{16} \mathrm{H}_{34}$ \\
\hline 43 & 19.103 & 3.00 & 1-Nonadecene & $\mathrm{C}_{19} \mathrm{H}_{38}$ \\
\hline 44 & 19.608 & 0.98 & 10-Heneicosene & $\mathrm{C}_{21} \mathrm{H}_{42}$ \\
\hline 45 & 20.009 & 3.21 & 1-Docosene & $\mathrm{C}_{22} \mathrm{H}_{44}$ \\
\hline 46 & 20.269 & 1.53 & 5-Nonadecene & $\mathrm{C}_{19} \mathrm{H}_{38}$ \\
\hline 47 & 20.885 & 2.46 & 9-Tricosene & $\mathrm{C}_{23} \mathrm{H}_{46}$ \\
\hline 48 & 21.249 & 0.20 & 10-Heneicosene & $\mathrm{C}_{21} \mathrm{H}_{42}$ \\
\hline 50 & 21.428 & 0.87 & 1-Pentene, 3,3-dimethyl- & $\mathrm{C}_{7} \mathrm{H}_{14}$ \\
\hline 51 & 21.717 & 2.54 & 1-Nonadecene & $\mathrm{C}_{19} \mathrm{H}_{38}$ \\
\hline 52 & 22.044 & 1.01 & 1-Docosene & $\mathrm{C}_{22} \mathrm{H}_{44}$ \\
\hline
\end{tabular}


Table 2 (continued)

\begin{tabular}{lllll}
\hline Sl. no. & Retention time & Area & Compound & Molecular formula \\
\hline 53 & 22.520 & 1.70 & 9-Tricosene & $\mathrm{C}_{23} \mathrm{H}_{46}$ \\
54 & 23.107 & 0.45 & Tetracosane & $\mathrm{C}_{24} \mathrm{H}_{50}$ \\
55 & 23.300 & 1.58 & Tetracosane & $\mathrm{C}_{24} \mathrm{H}_{50}$ \\
56 & 24.050 & 1.27 & Octacosane & $\mathrm{C}_{28} \mathrm{H}_{58}$ \\
57 & 25.469 & 0.66 & Tetracosane & $\mathrm{C}_{24} \mathrm{H}_{50}$ \\
58 & 26.145 & 0.55 & 9-Hexacosene & $\mathrm{C}_{26} \mathrm{H}_{52}$ \\
\hline
\end{tabular}

random scission reaction resulting in the formation of a large number of hydrocarbon species [19]. The formation of large number of alkene compounds in the oil by the thermal degradation of polyethylene and polypropylene can be explained due to the higher stability of carbon double bond $(C=C)$ as compared to single bond $(C-C)$ [20]. Calcium bentonite as a catalyst has number of acid sites on large surface area and the degradation of polymers on its surface is known to proceed by carbenium ion mechanism either by the abstraction of the hydride ion or the addition of a proton to the $\mathrm{C}-\mathrm{C}$ bonds of the polymer molecule or thermally degraded olefins [21].

\section{Properties of oil}

The physical properties of the oil obtained from different plastic samples obtained at optimum process conditions are summarised in the Table 3 and compared with the properties of different petro-fuels of gasoline, kerosene and diesel range [18]. The specific gravity of the different oils was found within the above said petro-fuel range. The viscosity of the plastic oils are higher than gasoline but within kerosene and diesel range. The flash point and fire point of the oils also resembles with that of gasoline. The calorific values of the oils are also high enough and at par with the petro-fuels. The distillation ranges of the plastic oils are very large and thus can be isolated into different fractions based on their boiling point to obtain gasoline, kerosene and diesel range fuels.

\section{Conclusion}

An optimised condition for temperature and catalyst concentration was established experimentally for the pyrolysis of different plastics to liquid fuel using calcium bentonite as catalyst in a batch reactor. Calcium bentonite is proved to be the efficient catalyst for pyrolysis of different plastics by improving the quality and quantity of oil and reaction time. The optimum condition for the higher plastics oil yield for all the plastic types in the experiments was at $500{ }^{\circ} \mathrm{C}$ with $1: 3$ catalysts to plastic ratio. The oil yield was about $80-90 \%$ by weight for different plastic samples at the optimum pyrolysis conditions. The oil contained only mixture of hydrocarbons and has matching fuel properties as that of fossil fuel.

Table 3 Fuel properties of oil

\begin{tabular}{|c|c|c|c|c|c|c|c|c|}
\hline \multirow{3}{*}{$\begin{array}{l}\text { Parameters } \\
\text { Colour }\end{array}$} & \multirow{3}{*}{$\begin{array}{l}\text { Test protocol } \\
-\end{array}$} & \multirow{3}{*}{$\begin{array}{l}\text { Gasoline } \\
\text { Yellow }\end{array}$} & \multirow{3}{*}{$\begin{array}{l}\text { Kerosene } \\
\text { Faint yellow }\end{array}$} & \multirow{3}{*}{$\begin{array}{l}\text { Diesel } \\
\text { Orange }\end{array}$} & \multicolumn{4}{|c|}{$\begin{array}{l}\text { Oil from catalytic pyrolysis at optimum condi- } \\
\text { tion }\end{array}$} \\
\hline & & & & & PP oil & LDPE oil & HDPE oil & Mixed plastics \\
\hline & & & & & \multicolumn{4}{|c|}{ Straw yellow } \\
\hline Specific gravity@ $15 / 15^{\circ} \mathrm{C}$ & I.S.1448: P.16 & $0.73-0.73$ & $0.78-0.82$ & $0.83-0.85$ & 0.721 & 0.769 & 0.789 & 0.751 \\
\hline Kinematic viscosity in Cst@ $30^{\circ} \mathrm{C}$ & I.S.1448:P: 25 & $1.076-1.03$ & $1.54-2.2$ & $2.4-5.3$ & 2.29 & 2.41 & 2.42 & 2.32 \\
\hline Pour point $\left({ }^{\circ} \mathrm{C}\right)$ & I.S.1448: P:10 & - & - & - & $<-40$ & & & \\
\hline Cloud point $\left({ }^{\circ} \mathrm{C}\right)$ & I.S.1448: P:10 & - & - & - & $<-40$ & & & \\
\hline Gross calorific value in $\mathrm{MJ} / \mathrm{kg}$ & I.S. 1448: P:6 & 46.86 & 45.46 & 42.51 & 44.37 & 42.12 & 43.19 & 43.28 \\
\hline Flash point by Abel $\left({ }^{\circ} \mathrm{C}\right)$ & I.S.1448: P:20 & -42 & $50-55$ & $55-60$ & -22 & & & \\
\hline Fire point $\left({ }^{\circ} \mathrm{C}\right)$ & I.S.1448: P:20 & -37 & 60 & 68 & -18 & & & \\
\hline Boiling point range $\left({ }^{\circ} \mathrm{C}\right)$ & I.S. 1448: P.18 & $40-205$ & $175-325$ & $150-350$ & $60-325$ & $70-345$ & $70-345$ & $65-345$ \\
\hline
\end{tabular}


Open Access This article is distributed under the terms of the Creative Commons Attribution 4.0 International License (http://creativecommons.org/licenses/by/4.0/), which permits unrestricted use, distribution, and reproduction in any medium, provided you give appropriate credit to the original author(s) and the source, provide a link to the Creative Commons license, and indicate if changes were made.

\section{References}

1. Hamad K, Kaseem M, Deri F (2013) Recycling of waste from polymer materials: an overview of the recent works. Polym Degrad Stab 98:2801-2812

2. Panda AK, Singh RK, Mishra DK (2010) Thermolysis of waste plastics to liquid fuel A suitable method for plastic waste management and production of value added products - a world prospective. Renew Sustain Energy Rev 14(1):233-248

3. Mohammad NS, Halim HR (2009) Pyrolysis of mixed plastics for the recovery of useful products. Fuel Process Technol 90(4):545-552

4. Adriana DS, Patrizia C, Fortunata G, Elisabetta B, Agostino N, Giorgio P (2013) Catalytic pyrolysis of polyethylene: a comparison between pillared and restructured clays. J Anal Appl Pyrol 104:479-484

5. Farah O, Joseph Z, Ala' a HAM, Kamal B (2014) Thermo-catalytic pyrolysis of waste polyethylene bottles in a packed bed reactor with different bed materials and catalysts. Energy Convers Manag $85: 1-6$

6. Imtiaz A, Ismail KM, Hizbullah K, Ishaq M, Razia K, Kashif G, Waqas A (2017) Pyrolysis of HDPE into fuel like products: evaluating catalytic performance of plain and metal oxides impregnated waste brick kiln dust. J Anal Appl Pyrol 124:195-203

7. Shogo K, Itaru H, Guido G, Tomohito K, Toshiaki Y (2015) Thermal decomposition of individual and mixed plastics in the presence of $\mathrm{CaO}$ or $\mathrm{Ca}(\mathrm{OH})_{2}$. J Anal Appl Pyrol 113:584-590

8. Devy KR, Mohamad AN, Paul TW (2017) Catalytic pyrolysis of waste plastics using staged catalysis for production of gasoline range hydrocarbon oils. J Anal Appl Pyrol 124:631-637

9. Kaixin L, Junxi L, Guoan Y, Piyarat W, Jing-Yuan W, Jun Z, Yanhui Y (2017) Fe-, Ti-, Zr- and Al-pillared clays for efficient catalytic pyrolysis of mixed plastics. Chem Eng J 317:800-809

10. Miandad R, Barakat MA, Rehan M, Aburiazaiza AS, Ismail IMI, Nizami AS (2017) Plastic waste to liquid oil through catalytic pyrolysis using natural and synthetic zeolite catalysts. Waste Manag 69:66-78

11. Kaltume A, Mohamad AN, Paul TW (2017) Aromatic fuel oils produced from the pyrolysis-catalysis of polyethylene plastic with metal-impregnated zeolite catalysts. J Energy Inst. https:// doi.org/10.1016/j.joei.10.009

12. Bianca PSS, Débora A, de Maria FVM, Cristiane AH (2018) Petrochemical feedstock from pyrolysis of waste polyethylene and polypropylene using different catalysts. Fuel 215:515-521

13. Chantal K, Sary A, Gaetan B, Khalil K, Mohand T (2017) Experimental study of catalytic pyrolysis of polyethylene and polypropylene over USY zeolite and separation to gasoline and diesel-like fuels. J Anal Appl Pyrol 127:31-37

14. Jiang G, Jie L, Zhiwei J, Xuecheng C, Xin W, Ewa M, Tao $\mathrm{T}$ (2014) Converting mixed plastics into mesoporous hollow carbon spheres with controllable diameter. Appl Catal B 152-153:289-299

15. Zeynep O, Naime AS, Timur D (2012) Catalytic degradation of polypropylene over alumina loaded mesoporous catalysts. Chem Eng J 207:421-425

16. Prosper AO, Noble B, Ahamada Z, Jeffrey S, Nicholas K (2018) Reverse engineering of plastic waste into useful fuel products. J Anal Appl Pyrol 130:285-293

17. Manos G, Isman Y, Papayannakos YN, Gangas NH (2001) Catalytic cracking of polyethylene over clay catalysts. Comparison with an ultrastable Y zeolite. Ind Eng Chem Res 40:2220-2225

18. Panda AK, Singh RK (2014) Conversion of waste polypropylene to liquid fuel using acid-activated kaolin. Waste Manag Res 32(10):997-1004

19. Turi E (1996) Thermal analysis. Brandrup and Immergut Pubs, Berlin

20. Pacakova V, Leclercq PA (1991) Gas chromatography-mass spectrometry and high-performance liquid chromatographic analyses of thermal degradation products of common plastics. J Chromatogr 555:229-237

21. Ayame A, Uemichi Y, Yoshida T, Kanoh H (1979) Gasification of polyethylene over solid catalysts (Part 3) gasification over calcium X zeolite in a fixed bed tubular flow reactor. J Jpn Petrol Inst $5: 280-287$

Publisher's Note Springer Nature remains neutral with regard to jurisdictional claims in published maps and institutional affiliations. 